\title{
Frequency of Different Ocular Conditions Leading to Ocular Morbidity in Pediatric Age Group at Dow University Hospital
}

\author{
Madiha Jawaid ${ }^{1}$, Mazhar-ul-Hassan², Saba Al-Khairy ${ }^{3}$, Farnaz Siddiqui ${ }^{4}$, Asad Azeem $^{5}$ \\ ${ }^{1-5}$ Department of Ophthalmology, Dow University Hospital, OJHA Campus
}

\begin{abstract}
Purpose: To determine the frequency of different ocular conditions leading to ocular morbidity in a tertiary care hospital.
\end{abstract}

Study Design: Descriptive cross sectional study.

Place and Duration of Study: Study was done in Dow University of medical sciences, from May 2018 to October 2018.

Methods: A total of 278 patients presenting in the eye out-patient department were included. Patients with unaided visual acuity of $6 / 6$ in both eye and no ocular abnormality were excluded from the study. Children with congenital syndromes like Down's syndrome, etc. leading to eye diseases were also excluded. All children underwent complete ocular examination. Data was analyzed by using SPSS version 22. Frequency and percentages were computed for gender and different ocular diseases e.g., myopia, hypermetropia, strabismus, Vernal Kerato-conjunctivitis, astigmatism, red eye, subconjunctival hemorrhage etc. Post-stratification chi-square test was applied with p-value $\leq 0.05$.

Results: Out of 278 participants of the study, there were 154 (55.4\%) males and $124(44.6 \%)$ females. Average age of the patients was $11.15 \pm 3.44$ years. Myopia and red eyes were the major causes of pediatric ocular morbidity i.e. $33.81 \%$ and $26.6 \%$ respectively. Comparison between two age groups showed that Myopia was higher in children with 11 to 15 years. Myopia and astigmatism were more common in females while subconjunctival hemorrhage was more in males.

Conclusion: Refractive errors are the commonest cause of childhood visual impairment in our setup. Correcting these preventable diseases can have a positive impact on the performance of children at school.

Key Words: Visual acuity, Pediatric, Myopia, Hypermetropia, Kerato-conjunctivitis.

How to Cite this Article: Jawaid M, Hassan M, Al-Khairy S, Siddiqui F, Azeem A. Frequency of Different Ocular Conditions Leading to Ocular Morbidity in Pediatric Age Group at Dow University Hospital. Pak J Ophthalmol. 2021, 37 (4): 366-369.

Doi: $10.36351 /$ pjo.v37i4.1202

Correspondence: Madiha Jawaid

Department of Ophthalmology

Dow University Hospital

OJHA Campus

Email: madihajawaid88@gmail.com

Received January 14, 2021

Accepted: July 24, 2021

\section{INTRODUCTION}

Decreased vision, whether congenital or acquired can negatively affect the learning of a child. It not only leads to bad quality of life but also has detrimental effects on the person's self-esteem caused by lack of employment opportunities and other social stigmatization. $^{1}$

According to WHO, about 5 percent of the global blind population comprises of children (approximately 
1.5 billion). The burden of blindness in the third world countries of Africa and Asia is three to four folds as compared to developed countries, contributing to 80$90 \%$ of the number of blind children worldwide. ${ }^{2}$ Every year, 5,000,000 children become blind and it is found that the majority of cases are caused by preventable ailments. ${ }^{3}$ The most common cause of visual impairment, all over the world, is refractive error. $^{4}$

According to the Pakistani data, the ratio of blindness among children was 1 per 10,000 children, which accumulated the total to 60,000 blind children. A possible contributing factor of congenital visual impairment is consanguineous marriages and maternal infections. $^{5}$

Among the visually impaired people in Pakistan, $66.7 \%$ are caused by cataracts. ${ }^{6}$ The range of ocular morbidity shows regional disparity, at a national level and sub-national level, often with respect to racial and genetic make-up. In the United States, squint, amblyopia and refractive error were the most common causes of visual disability in school going children. ${ }^{7}$ While in Nigeria, refractive error accounts for $25.7 \%$, allergic conjunctivitis makes up to $25.3 \%$, ocular trauma about $13.3 \%$ and corneal infections $12.5 \%{ }^{8}$ Although in Ethiopia, the most frequent reason of ocular diseases among kids was trachoma (33.7\%), while refractive errors came out to be $6.3 \%$ and nontrachomatous conjunctivitis was about 5.9\%.'

In India, about $30 \%$ of the visually impaired people acquire this disability before 20 years of age. ${ }^{\mathbf{1 0}}$ Ocular morbidities, in order of their prevalence included refractive error (23.6\%), vernal conjunctivitis $(17.32 \%)$ and infection of eye $(15.13 \%) .{ }^{11}$

The rationale of this study was to find out the causes of vision impairment in Dow University Hospital so that preventable diseases of pediatric age group could be tackled in time to avoid blindness.

\section{METHODS}

It was a descriptive cross sectional study done at Dow University Hospital, Karachi, from May 2018 to October 2018. The sample size was calculated by Open Epi calculator with prevalence of most common morbidity of refractive error as $23.67 \% .{ }^{11}$ With margin of error as $5 \%$ and $95 \%$ confidence interval, the sample size came out to be 278 . All patients of 5 to 15 years of age were included in this study. Patients belonging to either gender, presenting in the OPD for eye related problems were included. All patients, who had unaided visual acuity of $6 / 6$ in both eye and no ocular abnormality detected on detailed examination were excluded from the study. Children with congenital syndromes like Down's syndrome, etc. leading to eye diseases were also excluded.

After written informed consent from the parents of the children, all children underwent autorefractrometery (using RM8800 TOPCON) by a trained optometrist. Visual acuity was checked with Snellen chart. Cycloplegic refraction (by using Cyclopentolate hydrochloride $1.0 \%$ drops) was done in patients with visual acuity of less than 6/9 in the worse eye. Detailed examination of anterior segment and fundus of the eye was done with Slit lamp Biomicroscope (TOPCON SL-3C) and +90 diopter by a trainee ophthalmologist. The information collected from the patients was entered in a pre-designed Performa.

Data was analyzed by using SPSS version 22 . Mean with standard Deviation was calculated for age. Frequency and percentages were computed for gender, ocular morbidity e.g., myopia, hypermetropia, strabismus, Vernal Kerato-conjunctivitis, astigmatism, red eye, subconjunctival hemorrhage etc. Effect modifiers like age and gender were addressed through stratification. Post-stratification chi-square test was applied with $\mathrm{p}$-value $\leq 0.05$.

\section{RESULTS}

Out of 278 participants of the study, there were 154 (55.4\%) males and 124 (44.6\%) females. Average age of the patients was $11.15 \pm 3.44$ years. Myopia and red eyes were the major causes of pediatric ocular morbidity i.e. $33.81 \%$ and $26.6 \%$ respectively. For detailed causes of visual impairment refer to table 1 . Some patients had more than ocular diseases.

Table 1: Most Common Ocular Morbidity in Childhood $(n=278)$.

\begin{tabular}{lc}
\hline Cause of vision Impairment & Percentage \\
\hline Myopia & $33.81 \%$ \\
Red eye & $26.6 \%$ \\
Astigmatism & $12.95 \%$ \\
Hypermetropia & $6.47 \%$ \\
Vernal Kerato-conjunctivitis & $6.12 \%$ \\
Sub-conjunctival hemorrhage & $4.68 \%$ \\
Strabismus & $1.44 \%$ \\
\hline
\end{tabular}


Comparison between two age groups is shown in Table 2. Myopia was higher in age group with 11 to 15 years. All the other ocular diseases were similarly common in both age groups. Gender difference indicated that rate of decrease Vision, myopia, astigmatism and sub-conjunctival hemorrhage were also statistically significantly different between male and female as shown in table 3.

Table 2: Ocular Morbidity With Respect To Pediatric Age Groups.

\begin{tabular}{|c|c|c|c|}
\hline \multirow{2}{*}{ Ocular Morbidity } & \multicolumn{2}{|c|}{ Age Groups (Years) } & \multirow{2}{*}{ P-Value } \\
\hline & $5-10 n=105$ & $11-15 n=173$ & \\
\hline Decrease Vision & $56(53.3 \%)$ & $111(64.2 \%)$ & 0.074 \\
\hline Myopia & $21(20 \%)$ & $73(42.2 \%)$ & $0.0005 *$ \\
\hline Hypermetropia & $9(8.6 \%)$ & $9(5.2 \%)$ & 0.268 \\
\hline Strabismus & $3(2.9 \%)$ & $1(0.6 \%)$ & 0.122 \\
\hline $\begin{array}{l}\text { Vernal } \\
\text { Keratoconjunctivitis }\end{array}$ & $9(8.6 \%)$ & $8(4.6 \%)$ & 0.183 \\
\hline Astigmatism & $18(17.1 \%)$ & $18(10.4 \%)$ & 0.105 \\
\hline Red Eye & $32(30.5 \%)$ & $42(24.3 \%)$ & 0.257 \\
\hline $\begin{array}{l}\text { Sub-conjunctival } \\
\text { hemorrhage }\end{array}$ & $6(5.7 \%)$ & $7(4 \%)$ & 0.523 \\
\hline
\end{tabular}

Table 3: Ocular morbidity with respect to gender $n=278$.

\begin{tabular}{lccc}
\hline \multirow{2}{*}{ Ocular Morbidity } & \multicolumn{2}{c}{ Gender } & P- \\
& Male n= 154 & Female n= 124 & Value \\
\hline Decrease Vision & $81(52.6 \%)$ & $86(69.4 \%)$ & $0.005^{*}$ \\
Myopia & $43(27.9 \%)$ & $51(41.1 \%)$ & $0.021^{*}$ \\
Hypermetropia & $13(8.4 \%)$ & $5(4 \%)$ & 0.138 \\
Strabismus & $2(1.3 \%)$ & $2(1.6 \%)$ & 0.827 \\
Vernal & $10(6.5 \%)$ & $7(5.6 \%)$ & 0.769 \\
Keratoconjunctivitis & $14(9.1 \%)$ & $22(17.7 \%)$ & $0.033^{*}$ \\
$\begin{array}{l}\text { Astigmatism } \\
\text { Red Eye }\end{array}$ & $51(33.1 \%)$ & $23(18.5 \%)$ & 0.06 \\
$\begin{array}{l}\text { Sub-conjunctival } \\
\text { hemorrhage }\end{array}$ & $11(7.1 \%)$ & $2(1.6 \%)$ & $0.030^{*}$ \\
\hline
\end{tabular}

\section{DISCUSSION}

Visual disabilities of children affect their ability to learn, their wisdom, studying power and behavior. Statistics on diagnosis of ocular diseases in kids is the key for to carry out preventive and curative facilities.

In the present study, the average age of the patients was $11.15 \pm 3.44$ years. In a study by Mehari et al, the mean (SD) age of the study population was about 9.37 (4.95) years. ${ }^{12}$ Biswas et al had 714 patients including $416(58.26 \%)$ males and 298 (41.74\%) females. All the patients were divided into three broad groups, that is, 0-4, 5-9, and 10-14 years. Majority, that is, $70.73 \%$ of the study subjects were in the $10-14$ years of age group. ${ }^{11}$
Different studies had been done which concluded the burden of ocular morbidity among pediatric population. One of the study from Nigeria found that refractive error was the most common $(25.7 \%)$ while the vernal conjunctivitis was second commonest cause of visual morbidity. ${ }^{13}$ In another study in Tikrit, Iraq, allergic conjunctivitis (27\%) came out to be most prevalent and the second most common was refractive errors $(14.6 \%)$ followed by ocular trauma (13.8\%), infection $(12.7 \%)$, squint $(12.1 \%)$ and nasolacrimal duct obstruction (NLDO, 5.2\%). ${ }^{14}$ Active trachoma $(51.6 \%)$ was the most common in central Ethiopia in children under 10 years of age. ${ }^{15}$. In another study, refractive error was the commonest cause of decrease vision in children. ${ }^{16}$ This was consistent with our results.

Different studies show a variability in the prevalence of refractive error from $12 \%$ to $31 \% .^{17,18}$ Higher prevalence of refractive errors is seen among older age group of children which also endorse the results of our study. This could be because of lack of awareness among caretakers to recognize visual problem at an earlier stage.

In India, the prevalence of refractive errors ranges between $21 \%$ and $25 \%$ in India. ${ }^{19}$ Similar prevalence of refractive errors has been observed among different studies in Shimla, Kolkata and also in Ahmedabad. ${ }^{20}$

Data on prevalence of different causes of ocular morbidity from a particular region is a pre-requisite for planning preventive and curative services. There are insufficient data regarding hospital based studies on childhood ocular morbidity. To combat this, school eye screening programs should be strengthened so that visual impairment due to refractive errors could be reduced. Majority of the causes of ocular morbidity are preventable.

Limitations of this study are a single centered study with limited data. Measure to tackle these problems were also not included in this research. Large scale data from different provinces is required to make standard operating procedures to reduce ocular morbidity in the pediatric age group.

\section{CONLCUSION}

Refractive errors is the commonest cause of childhood visual impairment, which can be easily handled. Early detection and management can have a positive impact on the performance of children at school. The problem can be solved by simple spectacle correction. Ongoing 
repeated inspection platforms should be implemented to trim down the prevalence of ocular diseases in children.

\section{Ethical Approval}

The study was approved by the Institutional review board/Ethical review board. (OSP-IRB/2021/006)

\section{Conflict of Interest}

Authors declared no conflict of interest.

\section{REFERENCES}

1. Mehari ZA. Pattern of childhood ocular morbidity in rural eye hospital, Central Ethiopia. BMC Ophthalmol. 2014; 14 (1): 50.

2. Kishore S, Aggrawal P, Muzammil K, Singh S, Bhaskar Y, Bhaskar R. Ophthalmic morbidity in school children in hilly areas of Uttarakhand. Indian J Community Health, 2014; 26 (1): 56-60.

3. Saxena A. Nema A, Deshpande A. "Prevalence of refractive errors in school-going female children of a rural area of Madhya Pradesh, India.” J Clin Ophthalmol Res. 2019: 45-49.

4. Kumari VK, Lakshmi MS. Screening for simple myopia among high school children in Hyderabad city. J Evid Based Med. 2016; 3: 1097-1091.

5. Farrukh S, Latif MA, Klasra AH, Ali M. Pattern of pediatric eye diseases. Pakistan J Ophthalmol. 2015; 31 (3): 148 .

6. Jadoon MZ, Dineen B, Bourne RR, Shah SP, Khan MA, Johnson GJ, et al. Prevalence of blindness and visual impairment in Pakistan: the Pakistan national blindness and visual Impairment survey. ARVO. 2006; 47 (11): 4749-4755.

7. American Foundation for the Blind, "Statistical Snapshots from the American Foundation for the Blind." Retrieved from:

http://www.afb.org/info/blindness-statistics/2.

8. Achigbu E, Oguego N, Achigbu K. Spectrum of eye disorders seen in a pediatric eye clinic South East Nigeria." Nigerian J. 2017; 23 (2): 125.

9. Mohammed S, Abebe B. Common eye diseases in children of rural community in Goro district, Central Ethiopia. Ethiopia J Health Dev. 2005; 19: 148-152.

10. Gupta M, Gupta BP, Chauhan A, Bhardwaj A. Ocular morbidity prevalence among school children in Shimla, Himachal, north India. Indian J Opthalmol. 2009; 57 (2): 133.

11. Biswas J, Saha I, Das D, Bandyopadhyay S, Ray B, Biswas G. Ocular morbidity among children at a tertiary eye care hospital in Kolkata, West Bengal. Intern J pub Health, 2012; 56 (4): 293.
12. Mehari ZA. Pattern of childhood ocular morbidity in rural eye hospital, Central Ethiopia. BMC Ophthalmology, 2014; 14: 50.

13. Olusanya BA, Ugalahi MO, Ogunleye OT, Baiyeroju AM. Refractive errors among children attending a tertiary eye facility in Ibadan, Nigeria: highlighting the need for school eye health programs. Ann Ib Postgrad Med. 2019; 17 (1): 49-59.

14. Salmansheaps MS. Pediatric eye diseases among children attending outpatient eye department of Tikrit Teaching Hospital. Tikrit J Pharm Sci. 2010; 7 (1): 95 103.

15. Abebe B, Wondu A. Prevalence of trachoma and its determinants in Dalocha District, central Ethiopia. Ophthalmic Epidemiol. 2001; 8 (2-3): 119-125.

16. Paudel P, Ramson P, Naduvilath T, Wilson D, Phuong HT, Ho SM, et al. Prevalence of vision impairment and refractive error in school children in $\mathrm{Ba}$ Ria - Vung Tau province, Vietnam. Clin Exp Ophthalmol. 2014 Apr; 42 (3): 217-226. Doi: $10.1111 /$ ceo.12273.

17. Salma KCR, Hari T, Malla BA. Clinical profile of pediatric ocular morbidity in a tertiary eye care centre in western region of Nepal. Ann Pediatr Child Health, 2015; 3: 1070.

18. Gupta M, Gupta PB, Chauhan A, Bhardwaj A. Ocular morbidity prevalence among school children in Shimla, Himachal, North India. Indian J Ophthalmol. 2009; 57: 133-138.

19. Kumar R, Dabas P, Mehra M, Ingle GK, Saha R, Kamlesh. Ocular morbidity amongst primary school children in Delhi. Health Popul Perspect Issues, 2007; 30: $222-229$.

20. Santos-Bueso E, Dorronzoro-Ramírez E, GegúndezFernández JA, Vinuesa-Silva JM, Vinuesa-Silva I, García-Sánchez J. Causes of childhood blindness in a developing country and an underdeveloped country. J Fr Ophtalmol. 2015; 38 (5): 427-430.

\section{Authors' Designation and Contribution}

Madiha Jawaid; Senior Medical Officer: Concepts, Design, Literature Search, Data Acquisition, Data Analysis, Manuscript Editing, Manuscript Review.

Mazhar-ul-Hassan; Professor: Data Analysis, Manuscript Editing, Manuscript Review.

Saba Al-Khairy; Assistant Professor: Statistical Analysis, Manuscript Editing.

Farnaz Siddiqui; Assistant Professor: Manuscript Preparation.

Asad Azeem; Assistant Professor: Data Acquisition, Data Analysis. 